\title{
Patterns in the distribution and directional asymmetry of fleas living on the northern white-breasted hedgehog Erinaceus roumanicus
}

\author{
Krzysztof Dudek $^{1}$, Gábor Földvári ${ }^{2}$, Viktória Majláthová ${ }^{3}$, Igor Majláth ${ }^{4}$, Krisztina Rigó $^{2}$, Viktor Molnár ${ }^{5}$, Mária \\ Tóth $^{6}$, Lukasz Jankowiak ${ }^{7}$ and Piotr Tryjanowski ${ }^{1}$
}

\author{
${ }^{1}$ Institute of Zoology, Poznań University of Life Sciences, Poznań, Poland; \\ ${ }^{2}$ Department of Parasitology and Zoology, University of Veterinary Medicine, Budapest, Hungary; \\ ${ }^{3}$ Institute of Parasitology, Slovak Academy of Sciences, Košice, Slovakia; \\ ${ }^{4}$ Institute of Biology and Ecology, University of P. J. Šafárik in Košice, Košice, Slovakia; \\ ${ }^{5}$ Hannover Zoo, Hannover, Germany; \\ ${ }^{6}$ Department of Zoology, Hungarian Natural History Museum, Budapest, Hungary; \\ ${ }^{7}$ Department of Vertebrate Zoology and Anthropology, Institute for Research on Biodiversity, University of Szczecin, Szczecin, \\ Poland
}

\begin{abstract}
Fleas infecting northern white-breasted hedgehogs, Erinaceus roumanicus (Barrett-Hamilton), collected from 2009-2011 in Budapest (Hungary) were studied. A total of 305 white-breasted hedgehogs were captured and 1,251 fleas were collected. The flea community comprised two species, the hedgehog flea Archaeopsylla erinacei (Bouche, 1835) and the dog flea Ctenocephalides canis (Curtis, 1826), although the latter was only found on three hedgehogs. Fleas were found on half of the host specimens $(51 \%$; $\mathrm{n}=156)$ where their distribution was strongly aggregated. The sex ratio of $A$. erinacei was biased towards females and was correlated with host size. Interestingly, the sex ratio of fleas became more equal on heavier hosts. It had been expected that, under high competition, the sex ratio would be female biased because it is known that female ectoparasites dominate on poorer hosts. The body size of a random sample of 200 fleas (100 female and 100 male) was measured under a microscope. The analyses showed directional asymmetry in two features - the distance between the top of the head and the eye, and head length. In this two body traits the left side was significantly greater than right side in both sexes of A. erinacei. Our data shed light on the complex nature of the flea population infecting northern white-breasted hedgehogs in an urban area.
\end{abstract}

Keywords: morphometrics, Archaeopsylla erinacei, parasite morphology, co-infection

Hedgehogs are host to a variety of different parasites (Gaglio et al. 2010) and are often infected with the hedgehog flea, Archaeopsylla erinacei Bouche, 1835 (Beck and Clark 1997, Beck 2005), as well as other flea species, including the cat flea, Ctenocephalides felis (Bouche, 1835), $\operatorname{dog}$ flea C. canis (Curtis, 1826) and rat flea Nosopsyllus fasciatus Bosc, 1800 (see Beck 2005).

Hedgehogs also serve as a host for a variety of mite species, including Demodex erinacei (Hirst, 1917), Caparinia tripilis (Michael, 1889), and the agent of sarcoptic mange, Sarcoptes scabiei (Linnaeus, 1758) (see Tadmor and Rauchbach 1972). In temperate regions of Europe two tick species also commonly infect hedgehogs: Ixodes hexagonus (Leach, 1815) and I. ricinus Linnaeus, 1758 (see Földvári et al. 2011). As such, hedgehogs may act as pa- ratenic and reservoir hosts for a large variety of pathogens and parasites of significant epidemiological importance.

Archaeopsylla erinacei is a holometabolous insect that is obligatorily hematophagous in the adult stage. It is a nidicolous species, reproducing in the nests of breeding female hedgehogs, and young hedgehogs are infected before they leave the nest (Brinck and Löfqvist 1973). Fleas on hibernating hosts become inactive during both feeding and reproduction and start reproduction only after the host awakens (Marshall 1981a). Intensity of infection can exceed 900 fleas per host (Rosický 1957), with preference for the more humid ventral regions (forelegs, underarms, head, chest and abdominal areas) over the dryer dorsal areas of the body (Marshall 1981a). Both inter- and intraspecific host to host transfer is common (Marshall 1981a) and flea 
interchange is mediated by host behavioural interactions (Buckle 1978).

Hedgehog fleas are of epidemiological importance because they can bite humans and live with their hosts in urban areas (Bork et al. 1987). Fleas are capable of transmitting to humans the obligate intracellular bacterium, Rickettsia felis, that causes a typhus-like disease in humans (Perez-Osorio et al. 2008). Most (96\%) A. erinacei fleas were found to harbour R. felis in Germany (Gilles et al. 2009), and in a recent molecular analysis of the 2009-2010 fleas from the present study, all flea samples were positive for rickettsiae, with two samples (1.5\%) harbouring Rickettsia helvetica and $10 \%$ positive for a novel Rickettsia genotype (see Hornok et al. 2014). Additionally, Bartonella henselae (the causative agent of cat scratch disease in humans) was detected in one $A$. erinacei $(0.7 \%)$, and hemoplasmas of the hemofelis group were identified in seven other samples (5.2\%) (Hornok et al. 2014).

The aim of the present study was to obtain information about the ecology of fleas living on northern white-breasted hedgehog, Erinaceus roumanicus (Barrett-Hamilton), with a special focus on their distribution and morphology. Thus we observed prevalence, intensity and species richness of fleas on the hosts. We also report the sex ratio of fleas inhabiting the hedgehogs' integument and provide information on the sex distribution of these fleas while addressing the problem of sampling bias in sex ratio studies of external parasites (Marshall 1981b, Rózsa et al. 1996). The last aim of the study was to describe patterns of asymmetry for three body traits (body length, head length, and distance between the top of the head and the eye) in A. erinacei collected from hedgehogs while paying special attention to variation in the fleas' directional asymmetry in relation to parasite size and sex, and host size and sex.

\section{MATERIALS AND METHODS}

Field capture of hedgehogs was carried out for about $5 \mathrm{~h}$ after sunset once every month between May and October in 2009 and 2011 and from March through November 2010 at Margaret Island ( $47^{\circ} 52^{\prime} \mathrm{N}$; $\left.19^{\circ} 04^{\prime} \mathrm{E}\right)$, a $2.5 \mathrm{~km}$ long, $500 \mathrm{~m}$ wide $\left(0.965 \mathrm{~km}^{2}\right)$ island in the Danube river in central Budapest, Hungary. The island is mostly covered by landscaped parks and is a popular recreational area.

Hedgehogs were captured by hand with the aid of head lamps and were ear-tagged before release. Animal weights were determined and ectoparasites were removed and stored in 70\% ethanol. Ticks and fleas were counted and identified under a stereomicroscope using standard keys (Nosek and Sixl 1972, Szabó 1975, Hillyard 1996). To enhance the effectiveness of ectoparasite removal, anaesthesia was performed during 2010 and 2011 using a combination of ketamine ( $5 \mathrm{mg} / \mathrm{kg}$ body weight) and dexmedetomidine $(50 \mu \mathrm{g} / \mathrm{kg}$ body weight) administered intramuscularly. Atipamezole $(0.5 \mathrm{mg} / \mathrm{kg}$ body weight $)$ was administered $30 \mathrm{~min}$ after initial injection as an antidote for dexmedetomidine.

\section{Prevalence, intensity and species richness}

The prevalence, mean intensity of infection (sensu Bush et al. 1997) were determined for all species of fleas collected. To test flea aggregation on hosts the $\mathrm{k}$ exponent was used according to the method of Krasnov et al. (2005). The frequency distribution of fleas was calculated using the sample mean $(\overline{\mathrm{x}})$ and variance $\left(\mathrm{s}^{2}\right)$, with ' $\mathrm{k}$ ' estimated as $\mathrm{k}=\overline{\mathrm{x}}^{2} /\left(\mathrm{s}^{2}-\overline{\mathrm{x}}\right)$. The significance of the difference between observed and expected frequency distributions was determined using a $\chi^{2}$ test. Because $C$. canis was present in very low numbers (only three - see Results), we included only A. erinacei in further analyses. Since male and female hedgehogs, as well as adult and juvenile hedgehogs, were not different in flea prevalence and mean intensity (t-tests $p>0.05$ in each case), the data were pooled for further analyses.

\section{Sex ratio of fleas}

To analyse the sex ratio of fleas on each hedgehog we used a generalised linear model with a binomial error distribution. Since host characters may influence flea sex ratio the sex of flea individuals co-inhabiting the same host individual are not independent. We therefore controlled for this effect by introducing host individual as a random effect. We chose sex ratio, defined as the proportion of males, as the dependent variable and length and weight of the hedgehog as a predictor. Because we did not have all weight and length measurements, we did the analysis twice, once for weight (293 hedgehogs) and again for body length (77 hedgehogs). All models were checked for overdispersion and we did not find that it was issue in our models ( $p>0.05$ in all cases).

\section{Directional asymmetry}

A subsample of 200 fleas (100 males and 100 females) taken from randomly chosen hedgehogs (42 specimens) was measured using a stereomicroscope. Six measurements of each flea were taken: body length, head length and distance between the top of the head and the eye (all three repeated for left and right body side). This last measurement was chosen because components of the mouthparts with maxillae are located here; these structures play a crucial role in feeding and therefore are likely to exhibit variation in size. Initial analyses were performed to check for differences between sides of the fleas using a linear mixed model with a normal error distribution. We performed three repeated measurement analyses for each of the following: body length, head length, and distance between the top of the head and the eye. In each case the categorical variable was side and the repeated measurements we used were individual flea (repeated measurements on right and left side) and the individual hedgehog from which the flea came.

To analyse differences between sexes we used linear mixed models. In this case the dependent variables were the mean values of the left and right sides of the three above mentioned variables and the repeated measurement was the individual hedgehog.

In the last analysis of directional asymmetry we subtracted the left side measurements of flea traits from the right sides for the three measured traits, and the obtained results were dependent variables in three models. For modelling we also used a linear mixed model with a normal error distribution where hedgehog identification was the random effect. As independent variables we chose flea sex, hedgehog sex, weight of the hedgehog, body length of the hedgehog, and total tick load on the hedgehog. We analysed the independent variables only for 124 fleas (sampled from 24 hosts), because we did not possess host data for all fleas. 
Statistical analyses were performed using R ( R Core Team 2014) software following Zar (1999). For mixed models we used the lme4 package (Bates 2010).

\section{RESULTS}

\section{Prevalence, intensity and species richness}

Of the 305 hedgehogs checked for the occurrence of fleas, $51 \%$ (156 animals) were infected and a total of 1,251 fleas were collected. Mean intensity was 8.0 (95\% CL: 6.3-9.8) and ranged from one to 78 fleas. Two species of fleas were collected, the hedgehog flea (Archaeopsylla erinacei) and the dog flea (Ctenocephalides canis). However, dog fleas were found on only three hedgehogs - two male hedgehogs (14 and 5 fleas, respectively) and one female (one flea). On all hedgehogs infected with C. canis, A. erinace $i$ was also found (13, 22 and 32 fleas, respectively). For further analyses only the hedgehog fleas were used. Analysis of the frequency of distribution of the dominant flea species, A. erinacei, indicated an aggregated distribution pattern (Fig. 1), which differed significantly from the predicted poisson (random) distribution $(\mathrm{k}=0.1744$; $\mathrm{Z}=7.67$; $\mathrm{p}<0.0001$ ). Flea population size was also positively related to hedgehog body length $(\mathrm{p}<0.05)$.

\section{Sex ratio}

The sex ratio of the hedgehog fleas (531 males and 700 females) was significantly biased towards females ( $\chi^{2}$ with Yates correction $=15.23 ; \mathrm{p}<0.0001)$. There was a positive correlation between length and weight in both sexes (Spearman correlation test, females: $\mathrm{r}=0.556, \mathrm{n}=36$, $\mathrm{p}<0.001$; males: $\mathrm{r}=0.360, \mathrm{n}=40, \mathrm{p}<0.05$ ). Interestingly, we found a positive relationship between host weight, but not host body length (Table 1), and a shift of the sex ratio towards unity (Fig. 2).

\section{Directional asymmetry}

Directional asymmetry was detected in the distance between the top of the head and the eye: on the left side it was significantly longer than on the right side (left side: $0.156 \mu \mathrm{m} \pm 0.003 \mu \mathrm{m}$, right side: $0.145 \mu \mathrm{m} \pm 0.003 \mu \mathrm{m}$, Table 2). We also found significant differences between sides in the case of the length of the head (left side: $0.576 \mu \mathrm{m} \pm$ $0.006 \mu \mathrm{m}$, right side: $0.570 \mu \mathrm{m} \pm 0.006 \mu \mathrm{m}$, Table 2). For body length we did not find differences between sides.

Our measurements of fleas show that females have longer bodies, heads and distances between the tops of their heads and the eyes than males $(2.66 \mathrm{~mm} \pm 0.054 \mathrm{~mm} v \mathrm{~s}$ $2.19 \mathrm{~mm} \pm 0.050 \mathrm{~mm}, 0.593 \mathrm{~mm} \pm 0.005 \mathrm{~mm}$ vs $0.556 \mathrm{~mm}$ $\pm 0.005 \mathrm{~mm}, 0.159 \mathrm{~mm} \pm 0.002 \mathrm{~mm}$ vs $0.143 \mathrm{~mm} \pm$ $0.003 \mathrm{~mm}$, respectively; Table 3 ).

We found negative relationships between the host weight, tick infection and flea body length asymmetry, indicating that heavier hedgehogs and hedgehogs with higher tick infection were associated with more right side asymmetry of flea body length (Table 4).

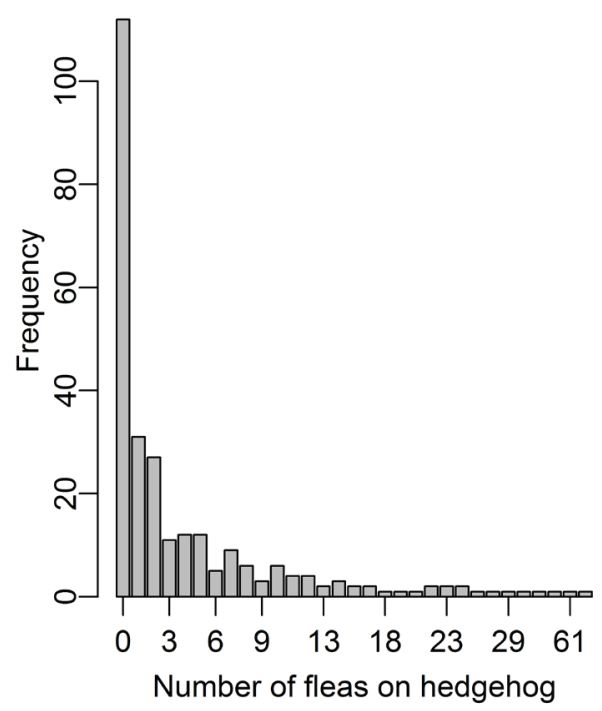

Fig. 1. Frequency distribution of the number of the flea Archaeopsylla erinacei (Bouche, 1835) of Erinaceus roumanicus (Barrett-Hamilton) $(\mathrm{k}=0.1744, \mathrm{Z}=7.67, \mathrm{p}<0.0001)$.

Table 1. Generalised linear models testing the relation between sex ratio (defined as the proportion of males) of the flea Archaeopsylla erinacei (Bouche, 1835) and weight and body length (body_lg) of Erinaceus roumanicus (Barrett-Hamilton). Body length is tested separately because we only had lengths for 77 of the 293 hedgehogs.

\begin{tabular}{llcccc}
\hline & & Estimate & SE/SD & z value & P \\
\hline Sex ratio & (intercept) & -0.857 & 0.249 & - & - \\
& weight & 0.850 & 0.375 & 2.264 & $\mathbf{0 . 0 2 4}$ \\
& hedgehog Id & 0.147 & 0.383 & - & - \\
\hline \multirow{2}{*}{ Sex ratio } & (intercept) & -2.041 & 1.242 & - & - \\
& body_lg & 0.073 & 0.051 & 1.446 & 0.148 \\
& hedgehog Id & 0.258 & 0.508 & - & - \\
\hline
\end{tabular}

SE/SD - standard error/standard deviation; $\mathrm{z}$ value - z-statistic; $\mathrm{P}$ - probability value; Id - identification number (random effect); bold number - significance at $\mathrm{P}<0.05$.

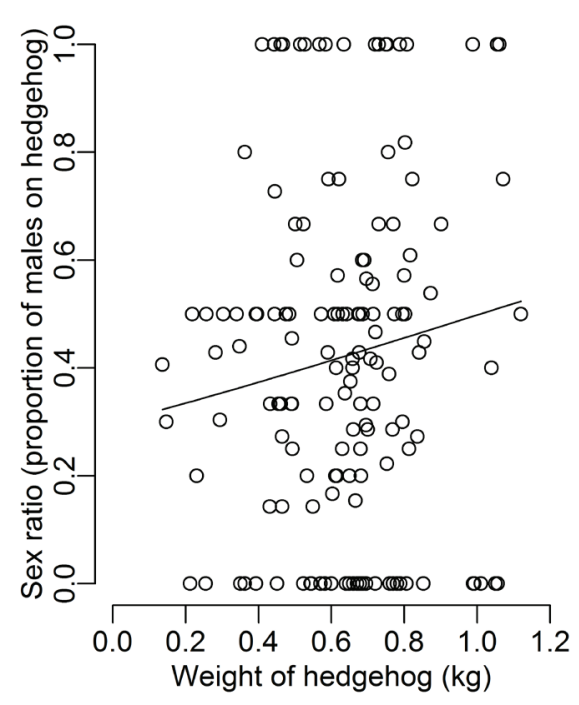

Fig. 2. Plot of binominal regression showing the relationship between sex ratio counted as the proportion of the male flea $\mathrm{Ar}$ chaeopsylla erinacei (Bouche, 1835) and weight of Erinaceus roumanicus (Barrett-Hamilton). 
Table 2. Results of linear mixed models testing the asymmetry between left and right side (sideR) of Archaeopsylla erinacei (Bouche, 1835) of Erinaceus roumanicus (Barrett-Hamilton).

\begin{tabular}{cccccc}
\hline & Estimate & SE/SD & df & t value & P \\
\hline Body length (Intercept) & 2.407 & 0.027 & - & - & - \\
sideR & 0.006 & 0.005 & 200.000 & 1.228 & 0.221 \\
flea Id & 0.094 & 0.307 & - & - & - \\
hedgehog Id & 0.004 & 0.064 & - & - & - \\
\hline Head length (intercept) & 0.576 & 0.003 & - & - & - \\
sideR & -0.006 & 0.002 & 200.000 & -2.666 & $\mathbf{0 . 0 0 8}$ \\
flea Id & $<0.001$ & 0.023 & - & - & - \\
hedgehog Id & $<0.001$ & 0.008 & - & - & - \\
\hline Top length (intercept) & 0.157 & 0.002 & - & - & - \\
sideR & -0.012 & 0.002 & 200.000 & -7.214 & $<\mathbf{0 . 0 0 1}$ \\
flea Id & 0.0001 & 0.0105 & - & - & - \\
hedgehog Id & $<0.001$ & 0.003987 & - & - & - \\
\hline
\end{tabular}

$\mathrm{SE} / \mathrm{SD}$ - standard error/standard deviation; $\mathrm{df}$ - degree of freedom; $\mathrm{t}$ value - t-statistic; $\mathrm{P}$ - probability value; Id - identification number (random effect); bold number - significance at $\mathrm{P}<0.05$.

Table 3. Results of linear mixed models testing between sex differences in body length, head length and distance from top of the head to the eye of the flea Archaeopsylla erinacei (Bouche, 1835) of Erinaceus roumanicus (Barrett-Hamilton).

\begin{tabular}{|c|c|c|c|c|c|}
\hline & Estimate & $\mathrm{SE} / \mathrm{SD}$ & $\mathrm{df}$ & t value & $\mathrm{P}$ \\
\hline Body length (intercept) & 2.660 & 0.025 & - & - & - \\
\hline sexM & -0.469 & 0.031 & 188.5 & -14.98 & $<0.001$ \\
\hline hedgehog Id & 0.003 & 0.054 & 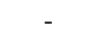 & - & - \\
\hline Head length (intercept) & 0.59 & 0.002 & - & - & - \\
\hline \multirow{2}{*}{$\begin{array}{l}\text { sexM } \\
\text { hedgehog Id }\end{array}$} & -0.03 & 0.003 & 176.52 & -11.44 & $<0.001$ \\
\hline & $<0.001$ & 0.004 & - & - & - \\
\hline \multirow[t]{2}{*}{ Top length } & 0.1 & 0.001 & - & - & - \\
\hline & -0.017 & 0.002 & 200.02 & -8.562 & $<0.001$ \\
\hline hedgehog Id & 0 & 0 & - & - & - \\
\hline
\end{tabular}

SE/SD - standard error/standard deviation; $d f$ - degree of freedom; $t$ value - t-statistic; $\mathrm{P}$ - probability value; sexM - sex differences (male vs female); Id - identification number (random effect); bold number - significance at $\mathrm{P}<0.05$.

\section{DISCUSSION}

The hedgehog flea (Archaeopsylla erinacei) and the dog flea (Ctenocephalides canis) are well-known ectoparasites of both Erinaceus roumanicus and its sibling species, Erinaceus europaeus (see Bolfíková and Hulva 2012). Interestingly, only three hedgehogs in the present study were infected with $C$. canis. Distributions of $A$. erinace $i$ were aggregated, an almost universal phenomenon amongst parasites (Shaw and Dobson 1995, Shaw et al. 1998, Dudek et al. 2016). Furthermore, our study also showed that on longer hedgehogs there were more fleas and ticks (Table 1) a not so surprising result given that larger hosts provide more skin surface area for ectoparasites (Dudek et al. 2016).

The sex ratio of hedgehog fleas was found to be significantly female biased. Whereas, such a differential sex ratio may be the result of a variety of factors, the main reason for such an occurrence in the field is likely related to gender differences in lifespan and/or the differential sensitivity of males and females to extrinsic factors such as air temperature or host defence (Krasnov et al. 2012). Significantly,
Table 4. Results of linear mixed models testing the relation between asymmetry of Archaeopsylla erinacei (Bouche, 1835) and sex, weight, body length (body_lg) and tick load (tick_total) of Erinaceus roumanicus (Barrett-Hamilton).

\begin{tabular}{|c|c|c|c|c|c|c|}
\hline & & Estimate & $\mathrm{SE} / \mathrm{SD}$ & df & t value & $P$ \\
\hline \multicolumn{2}{|c|}{ Body length(intercept) } & 0.093380 & 0.03047 & - & - & - \\
\hline & sexM & -0.019760 & 0.01451 & 124.00 & -1.361 & 0.176 \\
\hline & sex_hedgm & 0.000866 & 0.01636 & 124.00 & 0.053 & 0.958 \\
\hline & weight & -0.000093 & 0.00004 & 124.00 & -2.389 & 0.018 \\
\hline & body_lg & -0.001060 & 0.00077 & 124.00 & -1.38 & 0.170 \\
\hline & tick_total & -0.000395 & 0.00019 & 124.00 & -2.066 & 0.041 \\
\hline & hedgehog Id & 0.000000 & 0.00000 & - & - & - \\
\hline \multicolumn{2}{|c|}{ Head length (intercept) } & -0.007336 & 0.01672 & 5.61 & -0.439 & 0.677 \\
\hline \multicolumn{2}{|c|}{ sexM } & 0.003872 & 0.00578 & 122.40 & 0.67 & 0.504 \\
\hline \multirow{2}{*}{\multicolumn{2}{|c|}{$\begin{array}{l}\text { sex_hedgm } \\
\text { weight }\end{array}$}} & 0.012330 & 0.00840 & 6.88 & 1.469 & 0.186 \\
\hline & & 0.000005 & 0.00002 & 4.03 & 0.197 & 0.854 \\
\hline \multicolumn{2}{|r|}{ body_lg } & 0.000162 & 0.00040 & 6.00 & 0.405 & 0.700 \\
\hline \multirow{2}{*}{\multicolumn{2}{|c|}{$\begin{array}{l}\text { tick_total } \\
\text { hedgehog Id }\end{array}$}} & 0.000030 & 0.00011 & 4.60 & 0.277 & 0.794 \\
\hline & & 0.000140 & 0.01184 & - & - & - \\
\hline \multirow[t]{7}{*}{$\begin{array}{l}\text { Top of the } \\
\text { head length }\end{array}$} & (intercept) & 0.008213 & 0.01117 & 4.15 & 0.735 & 0.502 \\
\hline & sexM & 0.003736 & 0.00411 & 119.50 & 0.91 & 0.365 \\
\hline & sex_hedgm & 0.008594 & 0.00566 & 5.52 & 1.52 & 0.184 \\
\hline & weight & -0.000005 & 0.00002 & 2.79 & -0.341 & 0.757 \\
\hline & body_lg & 0.000065 & 0.00027 & 4.85 & 0.242 & 0.819 \\
\hline & tick_total & 0.000004 & 0.00007 & 3.47 & 0.049 & 0.964 \\
\hline & hedgehog Id & 0.000051 & 0.00717 & - & - & - \\
\hline
\end{tabular}

$\mathrm{SE} / \mathrm{SD}$ - standard error/standard deviation; $\mathrm{df}$ - degree of freedom; $\mathrm{t}$ value - t-statistic; $\mathrm{P}$ - probability value; sexM - sex differences of fleas (male $v s$ female); sex_hegm - sex differences of hedgehogs (male vs female); Id - identification number (random effect); bold number - significance at $\mathrm{P}<0.05$.

gender differences in resistance to starvation appear to be the rule in fleas, although the direction of this difference varies among species (Krasnov et al. 2012). Many flea species demonstrate a strong female bias (Marshall 1981b, Ryba et al. 1986, Li-Ming 1993, Grzywacz et al. 2005), but male bias has been also observed (Skuratowicz 1960, Peus 1968, Haitlinger 1973). Among 72 flea species belonging to various families, parasitic on various hosts, and inhabiting various geographical regions, 53 species were reported to be female-biased, 14 species to have a sex ratio close to unity (including $A$. erinacei), and only five species showed a male bias (Marshall 1981b). Interestingly, the current study indicates that an increase in the host size results in a shift of the sex ratio of fleas towards unity.

Environmental stressors (e.g. host condition) may affect the population of fleas not only by influencing the prevalence or sex ratio of the parasite but also its morphological asymmetry, as shown in previous studies on fluctuating and directional asymmetry (Møller 1992, Møller and Swaddle 1997, Radwan 2003, Tryjanowski and Adamski 2007). The directional asymmetry we report here is likely the result of environmental factors (Graham et al. 1994) and such asymmetries are assumed to impose a handicap on organisms because symmetry in most cases constitutes the optimal functional design. We suppose that, in the present study, access to food and blood quality (hence host quality) are the stressors for fleas (Tryjanowski and Adamski 2007). Digestion of blood is energetically costly, hence may affect the parasite body (Sarfati et al. 2005). Moreo- 
ver, studies on Daphnia spp. have shown that host starvation may influence the parasite population by decreasing their quality (Pulkkinen and Ebert 2004) and it is possible that this process also occurs in urban (often weaker) host populations.

The present study has shown that female fleas were longer (in all examined body parts) than males. Larger females are common in parasites (Charnov 1982) and, as in the case of insects, is likely an adaptation to maximise egg production (Ridley 1983). Our measurements indicate a directional asymmetry in two body traits of $A$. erinaceidistance between the top of the head and the eye, and the length of the whole head. These differences were detected in both flea sexes, and such directional asymmetry might be the result of stress in unstable environments (Graham et al. 1994). In the present case these stressors are likely parasite density leading to increased intra- and interspecific competition because studied hedgehogs have very high tick load (Foldvari et al. 2011). Lastly, we believe that the presence of asymmetry only on the head is linked to the ontogenic biology of the fleas. During development, the head of these insects is heavily sclerotised and asymmetry probably develops at an early stage and remains for the rest of the flea's life (Skuratowicz 1967). Interestingly, fleas from heavier hedgehogs, and from hedgehogs with greater tick loads, were more symmetrical in body length than others (Table 4). However, small sample size (only 124 fleas from 24 hedgehogs) might be the reason for this observation.

Our study showed that the hedgehog flea (A. erinacei) infected just over half of the white-breasted hedgehogs
(E. roumanicus) in the studied population. These fleas showed a strongly aggregated distribution on their host's body, and larger hosts, as measured by host length, harboured more fleas, likely the result of the availability of a larger habitat (skin) surface area. The sex ratio of hedgehog fleas was strongly female biased, a common occurrence in macroparasites; however, this ratio approached unity on larger hosts.

Overall, female fleas were longer than males and asymmetry in the length of the flea head was present, which is probably linked to either environmental stressors or to the developmental history of the insect. Our results provide a baseline for further examination of the complex nature of the flea population infecting northern white-breasted hedgehogs.

Acknowledgements. Analyses in this work were supported by the National Science Centre, Poland (K.D., P.T., grant number 2014/13/N/NZ8/02487), the János Bolyai Research Scholarship of the Hungarian Academy of Sciences (G.F.), and project Code ITMS 26220220116 based on the support of the Operational Programme 'Research and Development' funded from the European Regional Development Fund (rate 0.4). We thank Tim Sparks and Vincent A. Connors for proofreading and many valuable comments, and the Editor and two reviewers for their comments which improved the manuscript. Capturing, anaesthesia of hedgehogs and sample collection were carried out with the official permission from the Middle-Danube-Valley Inspectorate for Environmental Protection, Nature Conservation and Water Management, Hungary (KTVF: 22070-2/2010).

\section{REFERENCES}

Bates D.M. 2010: 1me4: Mixed-effects modeling with R. World Wide Web electronic publication, www.lme4.0.r-forge.r-project. org, 6/2017.

BECK W. 2005: Animal parasites and dermatophytes as a cause of epizoonoses in humans. Prakt. Tierarzt, Hannover 1: 426-434.

Beck W., Clark H.H. 1997: Differentialdiagnose medizinisch relevanter Flohspezies und ihre Bedeutung in der Dermatologie. Der Hautarzt 48: 714-719.

Bolfíková B., Hulva P. 2012: Microevolution of sympatry: landscape genetics of hedgehogs Erinaceus europaeus and E. roumanicus in Central Europe. Heredity 108: 248-255.

Bork K., Honomichl K., Hoede N. 1987: Flea bites caused by Archaeopsylla erinacei, the hedgehog flea. Hautarzt 38: 690692.

Brinck P., LöFQvisT J. 1973: The hedgehog Erinaceus europaeus and its flea Archaeopsylla erinacei. Zoon. Suppl. 1: 97-103.

BUCKLE A. 1978: The mark, release and recapture of fleas in a wild population of wood mice, Apodemus sylvaticus. J. Zool. 186 563-567.

Bush A.O., Lafferty K.D., Lotz J.M., Shostak A.W. 1997 Parasitology meets ecology on its own terms: Margolis et al. revisited. J. Parasitol. 83: 575-583.

Charnov E.L. 1982: The theory of sex allocation. Monogr. Popul. Biol. 18: 1-355.

Dudek K., Skórka P., Sajkowska Z.A., Ekner-Grzyb A., Dudek M., Tryjanowski P. 2016: Distribution pattern and number of ticks on lizards. Ticks Tick Borne Dis. 7: 172-179.

Földvári G., Rigó K., Jablonszky M., Biró N., Majoros G., MolnáR V., Tóth M. 2011: Ticks and the city: ectoparasites of the Northern white-breasted hedgehog (Erinaceus roumanicus) in an urban park. Ticks Tick Borne Dis. 2: 231-234.
Gaglio G., Allen S., Bowden L., Bryant M., Morgan E.R. 2010: Parasites of European hedgehogs (Erinaceus europaeus) in Britain: epidemiological study and coprological test evaluation. Eur. J. Wildl. Res. 56: 839-844.

Gilles J., Silaghi C., Just F., Pradel I., Pfister K. 2009: Polymerase chain reaction detection of Rickettsia felis-like organism in Archaeopsylla erinacei (Siphonaptera: Pulicidae) from Bavaria, Germany. J. Med. Entomol. 46: 703-707.

Graham J.H., Freeman D.C., Emlen J.M. 1994: Antisymmetry, directional asymmetry, and dynamic morphogenesis. In: T.A. Markow (Ed.), Developmental Instability: Its Origins and Evolutionary Implications. Springer, Tempe, pp. 123-139.

Grzywacz B., Blaski M., Wojciechowski W. 2005: Morphological variability of Ceratophyllus hirundinis (Curtis, 1826), (Insecta, Siphonaptera). Acta Entomol. Siles. 2: 41-50.

Haitlinger R. 1973: To the knowledge of Siphonaptera and Anoplura fauna of the small mammals in Hungary. Parasitol. Hung. 6: 205-214.

Hillya RD P.D. 1996: Ticks of North-West Europe. Field Studies Council, London, $178 \mathrm{pp}$.

Hornok S., Földvári G., Rigó K., Meli M.L., Tóth M., Molnár V., Gönczi E., Farkas R., Hofmann-Lehmann R. 2014: Vector-borne agents detected in fleas of the northern white-breasted hedgehog. Vector Borne Zoon. Dis. 14: 74-76.

Krasnov B.R., Bordes F., Khokhlova I.S., Morand S. 2012: Gender-biased parasitism in small mammals: patterns, mechanisms, consequences. Mammalia 76: 1-13.

Krasnov B.R., Morand S., Khokhlova I., Shenbrot G., Hawlena H. 2005: Abundance and distribution of fleas on desert rodents: linking Taylor's power law to ecological specialization and epidemiology. Parasitology 131: 825-837. 
Li-Ming M. 1993: The sex ratios of some fleas in north China. Acta Entomol. Sin. 1: 010.

Marshall A.G. 1981a: The Ecology of Ectoparasitic Insects. Academic Press, London, $446 \mathrm{pp}$.

Marshall A.G. 1981b: The sex ratio in ectoparasitic insects. Ecol. Entomol. 6: 155-174.

Møller A.P. 1992: Parasites differentially increase the degree of fluctuating asymmetry in secondary sexual characters. J. Evol. Biol. 5: 691-699.

Møller A.P., Swaddle J.P. 1997: Asymmetry, Developmental Stability and Evolution. Oxford University Press, Oxford, pp. 134-152.

Nosek J., Sixl W. 1972: Central European ticks (Ixodoidea). Key for determination. Jahrb. Naturwissens. Abt. Joanneum 1: 6192.

Pérez-Osorio C.E., Zavala-Velázquez J.E., León J.J.A., Zavala-Castro J.E. 2008: Rickettsia felis as emergent global threat for humans. Emerg. Infect. Dis. 14: 1019.

Peus F. 1968: Über die beiden Bernstein-Flöhe (Insecta, Siphonaptera). Paläontol. Z. 42: 62-72.

Pulkininen K., Ebert D. 2004: Host starvation decreases parasite load and mean host size in experimental populations. Ecology 85: 823-833.

R Core Team 2014: R: A language and environment for statistical computing. R Foundation for Statistical Computing, Vienna, https://www.r-project.org/

RADWAN J. 2003: Inbreeding not stress increases fluctuating asymmetry in the bulb mite. Evol. Ecol. Res. 5: 287-295.

Ridley M. 1983: The Explanation of Diversity: the Comparative Method and Adaptations for Mating. Clarendon, Oxford.

Rosick Ý B. 1957: [Fleas - Aphaniptera, Fauna of the Czechoslovak Socialist Republic, Volume 10] Publ. House of the Czechoslovak Academy of Science, Praha, 446 pp. (In Czech.)
Rózsa L., RÉKÁsI J., Reiczigel J. 1996: Relationship of host coloniality to the population ecology of avian lice (Insecta: Phthiraptera). J. Anim. Ecol. 65: 242-248.

Ryba J., Rödl P., Bartoš L., Daniel M., Černý V. 1986: Some features of the ecology of fleas inhabiting the nests of the suslik (Citellus citellus (L.)). I: Population dynamics, sex ratio, feeding, reproduction. Folia Parasitol. 33: 265-275.

Sarfati M., Krasnov B.R., Ghazaryan L., Khokhlova I.S., Fielden L.J., Degen A.A. 2005: Energy costs of blood digestion in a host-specific haematophagous parasite. J. Exp. Biol. 208: 2489-2496.

Shaw D., Dobson A. 1995: Patterns of macroparasite abundance and aggregation in wildlife populations: a quantitative review. Parasitology 111: 111-133.

Shaw D., Grenfell B., Dobson A. 1998: Patterns of macroparasite aggregation in wildlife host populations. Parasitology 117: 597-610.

Skuratowicz W. 1960: [Contributions to the knowledge of fleas (Aphaniptera) of the Białowieża Forest.] Annal. Zool. 19: 1-32. (In Polish.)

Skuratowicz W. 1967: [Fleas - Siphonaptera (Aphaniptera)]. Panstwowe Wydawnictwo Naukowe, Warszawa, 141 pp. (In Polish.)

Szabo I. 1975: [Fleas - Siphonaptera.] In: H. Sándor (Ed.), Fauna Hungariae Volume XV, Academic Press, Budapest, 97 pp. (In Hungarian).

Tadmor A., Rauchbach K. 1972: Berliner Munchener Tierarztl. Wochenschrift 85: 214-214.

Tryjanowski P., Adamski Z. 2007: Sex differences in fluctuating asymmetry of body traits in chewing lice Docophorulus coarctatus (Phthiraptera: Ischnocera). Parasitol. Res. 101: 1289-1294.

ZAR J.H. 1999: Biostatistical Analysis. Second Edition. Prentice Hall, New Jersey, 663 pp.

Received 7 February 2017

Accepted 23 June 2017

Published online 4 August 2017

Cite this article as: Dudek K., Földvári G., Majláthová V., Majláth I., Rigó K., Molnár V., Tóth M., Jankowiak L., Tryjanowski P. 2017: Patterns in the distribution and directional asymmetry of fleas living on the northern white-breasted hedgehog Erinaceus roumanicus. Folia Parasitol. 64: 026. 